Prediction of human iron bioavailability using rapid cELISAs for human plasma hepcidin

Journal Article

Author(s):

Stoffel, Nicole U.; Zeder, Christophe; Fort, Eloïse; Swinkels, Dorine W.; Zimmermann, Michael B.; Moretti, Diego

Publication date:

2017-07

Permanent link:

https://doi.org/10.3929/ethz-b-000233020

Rights / license:

In Copyright - Non-Commercial Use Permitted

Originally published in:

Clinical Chemistry and Laboratory Medicine 55(8), https://doi.org/10.1515/cclm-2017-0097 
Nicole U. Stoffel*, Christophe Zeder, Eloïse Fort, Dorine W. Swinkels, Michael B. Zimmermann and Diego Moretti*

\section{Prediction of human iron bioavailability using rapid c-ELISAs for human plasma hepcidin}

DOI 10.1515/cclm-2017-0097

Received February 1, 2017; accepted April 25, 2017; previously published online June 17, 2017

\section{Abstract}

Background: Hepcidin is the central systemic regulator of iron metabolism, but its quantification in biological fluids is challenging. Rapid, accurate and user-friendly methods are needed. Our aim was to assess the ability of hepcidin as measured by three different c-ELISA assays to predict iron bioavailability in humans.

Methods: The three assays used were commercially available DRG and Peninsula assays and the c-ELISA method performed at Radboud University Medical Centre, Nijmegen, The Netherlands (Hepcidinanalysis.com), validated by comparative measurements with time-of-flight mass spectrometry. We analyzed plasma samples $(n=37)$ selected to represent a broad range of hepcidin concentrations from a subgroup of healthy, iron-depleted women in a study assessing fractional absorption from iron supplements.

Results: In single regressions, all three c-ELISA assays were predictors of fractional iron absorption: $R^{2}=0.363$ (DRG), $\mathrm{R}^{2}=0.281$ (Peninsula) and $\mathrm{R}^{2}=0.327$ (Hepcidinanalysis.com). In multiple regressions, models including hepcidin measured with either DRG-, Peninsula or Hepcidinanalysis.com explained 55.7\%, 44.5\% and 52.5\% of variance in fractional absorption, and hepcidin was a strong predictor of fractional absorption irrespective of

*Corresponding authors: Nicole U. Stoffel, Department of Health Science and Technology, Laboratory of Human Nutrition, ETH Zürich, Schmelzbergstr. 7, 8092 Zürich, Switzerland, Phone: +4144 6324315 , Fax: +41 446321470 , E-mail: nicole.stoffel@hest.ethz.ch. http://orcid.org/0000-0001-5953-0610; and Diego Moretti, Department of Health Science and Technology, Laboratory of Human Nutrition, ETH Zürich, Schmelzbergstr. 7, 8092 Zürich, Switzerland, Phone: +41 4463284 36, Fax: +41 4463214 70,

E-mail: diego.moretti@hest.ethz.ch

Christophe Zeder, Eloïse Fort, Michael B. Zimmermann: Department of Health Science and Technology, Laboratory of Human Nutrition, ETH Zürich, Zürich, Switzerland

Dorine W. Swinkels: Department of Laboratory Medicine, Translational Metabolic Laboratory, Radboud University Medical Center, Nijmegen, The Netherlands; and Hepcidinanalysis.com, Laboratory Medicine, Nijmegen, The Netherlands the hepcidin assays used. However, we found significant differences in absolute values for hepcidin between different methods. Both the DRG assay's $(y=0.61 x+0.87$; $\left.\mathrm{R}^{2}=0.873\right)$ and the Peninsula assay's measurements $\left(y=1.88 x+0.62 ; R^{2}=0.770\right)$ were correlated with Hepcidinanalysis.com.

Conclusions: The biological variability in plasma hepcidin, (inter-sample CV) was 5-10-fold higher for both the Peninsula and DRG assay than the analytical variably (inter-run within-sample CV) suggesting substantial discriminatory power to distinguish biological hepcidin variation. Between methods, prediction of iron bioavailability in generally healthy iron depleted subjects appears comparable.

Keywords: anemia of chronic disease; hepcidin; iron absorption; iron deficiency anemia; iron overload.

\section{Introduction}

Hepcidin (PHep) is an iron regulatory hormone synthesized by the liver that responds to systemic iron demands, such as body iron stores, erythropoietic drive and inflammation $[1,2]$. It binds to the only known cellular iron exporter, ferroportin, leading to degradation and decreased export of intracellular iron from enterocytes, macrophages and hepatocytes $[2,3]$. Because of its iron-regulatory function, PHep may play an important role in diagnosis of iron related diseases [4]. An example is the determination of PHep to diagnose iron deficiency anemia (IDA) when it occurs in concomitance with chronic disease (ACD) [5, 6]. PHep concentrations may predict which patient will respond to oral iron supplementation [7], and PHep may be used to optimize iron supplementation schedules in humans [8]. However, measuring PHep is technically challenging, as it is a small (25 amino acid) cysteine-rich cationic peptide $[9,10]$. In addition, due to its compact structure and the high degree of conservation among a wide range of species, it elicits a diminished immune response in host animals, complicating the generation of antibodies. Nonetheless, immunochemical based-assays for PHep measurement are commercially available. Although mass 
spectrometry-based methods (liquid chromatography, LC-MS; surface-enhanced laser desorption/ionizationtime-of-flight, SELDI-TOF-MS; and matrix-assisted laser desorption/ionization-time-of-flight, MALDI-TOF-MS) are currently the methods of choice to quantify PHep due to their higher precision and because they can distinguish the bioactive hepcidin- 25 isoform from the smaller $\mathrm{N}$-truncated isoforms [11], their disadvantage is that they require expensive equipment and specialized training. As PHep levels in subjects with iron deficiency (ID) are usually low, a measurement method should ideally have a low limit of detection [12]. The aims of this study were to: (a) compare the ability of the three PHep c-ELISA assays to predict iron bioavailability in humans measured by using stable iron isotope techniques; and (b) compare the performance of two commercially available c-ELISA assays for PHep to an established c-ELISA method previously validated and compared with a MS-based method.

\section{Materials and methods}

We selected 37 plasma hepcidin samples collected from a previously conducted study assessing fractional absorption (FA) from iron supplements in iron depleted (plasma ferritin $\leq 20 \mu \mathrm{g} / \mathrm{L}$ ) but otherwise healthy female subjects. Iron absorption was assessed by measuring the amount of stable isotopic tracers incorporated in red blood cells 14 days post-administration [8]. We collected whole blood into EDTA-containing tubes by venipuncture from a forearm vein and measured hemoglobin $(\mathrm{Hb})$ with Coulter Counter AcT8 (Beckman Coulter, Nyon, Switzerland). We separated plasma and we froze aliquots at $-20^{\circ} \mathrm{C}$ on the day of collection for later determination of iron status and inflammation parameters, as well as PHep. We measured plasma ferritin (PF) and soluble transferrin receptor (sTfR) by using a multiplex ELISA method [13]. PHep was first measured at the Radboud University Medical Centre, Nijmegen, The Netherlands with a sensitive c-ELISA method [11] (Hepcidinanalysis.com) previously validated and compared with TOF-MS measurements. We conducted these initial measurements in February 2014. We then selected 37 plasma samples that represented a wide range of PHep values from 0.4 to $26.9 \mathrm{nM}$ and further measured PHep using plasma from a separate aliquot, with the same sample volume as the original sample used to determine PHep. Samples selected originated from 14 female subjects. Fractional iron absorption (FA) was available for 31 time points/samples. Fourteen samples among the selected were baseline samples collected prior any iron supplementation. We used two different commercially available c-ELISA assays: (1) DRG Hepcidin 25 (bioactive) HS ELISA (DRG Instruments GmbH, Marburg, Germany; Lot\#:314K035, EIA-5782) and (2) Peninsula Hepcidin 25 (human) EIA Kit (Peninsula Laboratories International, Inc., San Carlos, CA, USA; Lot\#: A15015 and A15117, S-1337.0001). The Penisula kit was previously named Bachem kit and was marketed and reported in the literature under this name [14, 15]. We ordered all kits in April-May 2015. We performed these additional PHep measurements in April-June 2015 according to the manufacturer's instructions. The Peninsula kit provides seven different protocols for analysis. We performed the analysis using protocol $\mathrm{V}$, as the manufacturer indicated this as the most commonly used extraction-free assay. According to this protocol, a seven-point standard curve was recommended. After first trials, in order to improve the fit of the standard curve, we prepared a nine point standard curve: $0,25,12.5,6.25,3.12,1.61,0.805,0.4,0.2$ and $0.05 \mathrm{ng} / \mathrm{mL}$, which resulted in improvement for standard curve fit. For both methods, we analyzed all samples in duplicate.

\section{Ethical considerations}

We recruited subjects from the student population at ETH and the University of Zürich, Switzerland. The protocol of the studies was reviewed and approved by the Ethical Review Committee of the ETH Zürich and registered in a public clinical trial registry (clinical trial. gov, NCT01785407 and NCT02050932).

\section{Statistical analyses}

We conducted statistical analysis with Excel (Microsoft, Version 2010) and SPSS (IBM SPSS statistics, Version 22). We checked normality with the Kolmogorov-Smirnov test. If data was not normally distributed, data was log transformed. Data for PHep (from all three assays) and iron absorption was normally distributed after log transformation (Log10). Pearson's correlation and linear multiple regression models were fitted to assess the predictive power of PHep measured by the three different c-ELISA methods on FA. We conducted regression analysis with FA as dependent variable and PHep, sTfR, Hb, PF and BMI as independent variables. We used log-transformed data (Log10) for regression analysis. In addition, we used Pearson's correlation analysis including only samples that were taken before iron supplementation to determine predictive power of PHep on FA in the low PHep concentration range. Pearson correlation coefficients are presented as $\mathrm{r}$, whereas regressions coefficients of determination are presented as $\mathrm{R}^{2}$.

We determined intra-run and inter-run variability by calculating the coefficient of variation (CV). We determined intra-run variability based on one sample in eight replicates on a single plate for both the DRG and the Peninsula method.

\section{$\mathrm{CV}_{\text {intra }}=$ Mean of the SD of the duplicates/Mean of the duplicates}

We calculated inter-run variability with samples analyzed on two different plates in series ( $\mathrm{n}=8$ for DRG, $\mathrm{n}=1$ for Peninsula). Values assessed by Hepcidinanalysis.com were $0.88,1.00,0.38,0.65,1.10$, 26.10, 3.60, $6.50 \mathrm{nM}$ ( $\mathrm{n}=8$ for DRG) and $0.70 \mathrm{nM}$ ( $\mathrm{n}=1$ for Peninsula).

\section{$\mathrm{CV}_{\text {inter }}=\mathrm{SD}$ of the mean of the duplicates/Mean of the duplicates}

Using the method of Bland and Altman [16] with regression lines and Pearson's correlations, we investigated the equivalence between the DRG and the Peninsula c-ELISA, as well as the equivalence between these two methods and the Hepcidinanalysis.com assay.

\section{Results}

The median age of the women was 24 years (range $=21-42$ years) and median BMI was $20.9 \mathrm{~kg} / \mathrm{m}^{2}$ 
(range $=17.6-25.2 \mathrm{~kg} / \mathrm{m}^{2}$ ). There were no anemic subjects in the studies, and the prevalence of ID, defined as $\mathrm{PF}<15$ $\mu \mathrm{g} / \mathrm{L}$ and/or sTfR $>8.3 \mathrm{mg} / \mathrm{L}$, was $43 \%$ with median of PF of 15.6 (range $=7.1-32.0 \mu \mathrm{g} / \mathrm{L})$ and of sTfR of 4.5 (range $=2.4-$ $7.4 \mathrm{mg} / \mathrm{L}$ ) (Table 1).

As shown in Figure $1 \mathrm{~A}-\mathrm{C}$, Pearson's correlations of PHep concentrations with FA for the DRG, Peninsula and Hepcidinanalysis.com assays were $r=-0.602(p<0.001)$, $\mathrm{r}=-0.530(\mathrm{p}<0.01)$ and $\mathrm{r}=-0.572(\mathrm{p}<0.01)$, respectively. Correlation analysis conducted only including baseline samples $(n=14)$ taken before iron supplementation, was not significant.

In single regression analysis, all three c-ELISA assays were predictors of FA: $\mathrm{R}^{2}=0.363(\mathrm{DRG}), \mathrm{R}^{2}=0.281$ (Peninsula) and $\mathrm{R}^{2}=0.327$ (Hepcidinanalysis.com). We performed a hierarchical regression analysis with three separate models for the three different PHep assays, and included $\mathrm{Hb}, \mathrm{PF}$, TfR and BMI as additional covariates; the overall models including the PHep values from the DRG-, Peninsula and Hepcidinanalysis.com assays explained $55.7 \%, 44.5 \%$ and $52.5 \%$ of the variance, respectively. PHep was the strongest predictor of FA in all the three models. The standardized regression coefficients $(\beta)$ between PHep and FA were -0.603 (DRG), -0.452 (Peninsula) and -0.545 (Hepcidinanalysis.com) (Table 2). The ratio between the standard error of $\beta$ and $\beta$ was $0.14,0.21$ and 0.12 for DRG, Peninsula and Hepcidinanalysis.com, respectively.

Reproducibility, expressed as intra-run procedure CV in the same sample (level assessed by Hepcidinanalysis.com was $2.70 \mathrm{nM})$ was $13.9 \%(\mathrm{n}=8)$ for $\mathrm{DRG}$, which is higher than the $\mathrm{CV}$ reported by the manufacturer $(\mathrm{CV} \approx 5.5 \%, \mathrm{n}=20)$. Equivalence between runs, expressed as inter-run procedure CV in the same sample was $15.4 \%$ $(\mathrm{n}=8)$ over the range of concentrations from 0-30.5 $\mathrm{nM}$ for DRG. The inter-sample, intra-run CV for DRG was 109.7\% $(\mathrm{n}=37)$. For Peninsula, the intra-run procedure $\mathrm{CV}$ was $11.6 \%(n=8)$ (level assessed by Hepcidinanalysis.com was $1.00 \mathrm{nM})$, the inter-run procedure $\mathrm{CV}$ was $10.7 \%$ and the inter-sample, intra-run CV was 55.7\% $(n=37)$. Figure $2 A-C$

Table 1: Study population characteristics.

\section{Subject characteristics $(n=14)$}

Age, years ${ }^{\mathrm{a}}$

BMI, $\mathrm{kg} / \mathrm{m}^{2 \mathrm{~b}}$

$24(23-25)$

Hemoglobin, $\mathrm{g} / \mathrm{dL}^{\mathrm{b}}$

$20.8 \pm 1.9$

Plasma ferritin, $\mu \mathrm{g} / \mathrm{L}^{\mathrm{a}}$

$13.7 \pm 0.7$

Plasma transferrin receptor, $\mathrm{mg} / \mathrm{L}^{\mathrm{a}}$

$15.6(11.8-26.7)$

$4.5(3.8-6.1)$

${ }^{a}$ All such data were medians (IQR). ${ }^{b}$ All such data were means \pm SD. Conversion factor to SI units for hemoglobin is 10 .
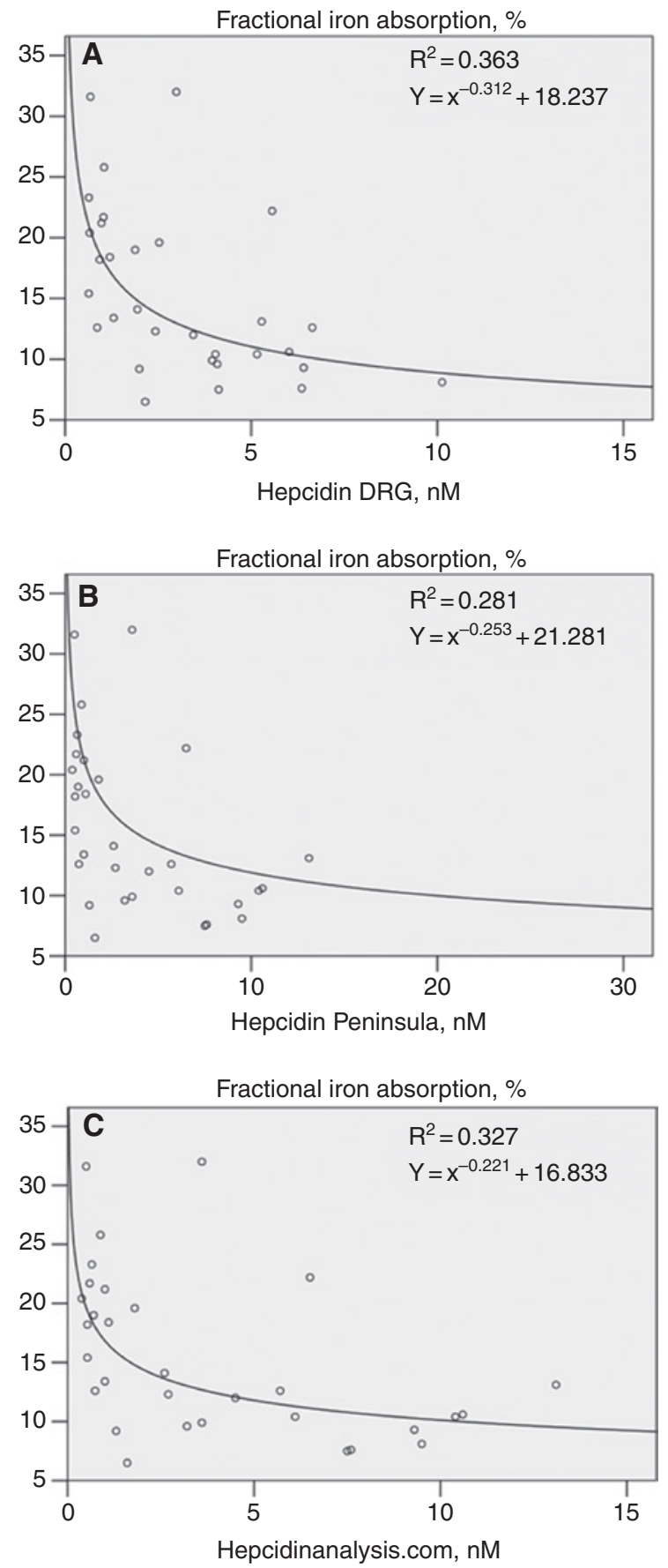

Figure 1: Plasma hepcidin analysis: biological relevance. Correlation between plasma hepcidin (PHep) and fractional iron absorption. Log transformed (Log10) data was used. PHep determined by: (A) DRG; (B) Peninsula; (C) Hepcidinanalysis.com.

shows the level of equivalence between the three assays using Bland-Altman plots.

As shown in Figure 2D-F, the correlations between the Hepcidinanalysis.com and DRG assays and the Hepcidinanalysis.com and Peninsula assays were $r=0.962$ $(p<0.001)$ and $r=0.890(p<0.001)$, respectively, while 
Table 2: Predictors of fractional iron absorption for the DRG-, the Peninsula- and the Hepcidinanalysis.com model.

\begin{tabular}{|c|c|c|c|c|}
\hline & $\mathbf{R}^{2}$ & B & Standard error of B & Standardized $\beta$ \\
\hline Model I & 0.557 & & & \\
\hline Hepcidin DRG, nM & & -0.312 & 0.086 & $-0.603^{a}$ \\
\hline Hemoglobin, g/dL & & 3.964 & 0.756 & $0.445^{b}$ \\
\hline Plasma ferritin, $\mu \mathrm{g} / \mathrm{L}$ & & -0.107 & 0.181 & -0.117 \\
\hline Transferrin receptor, $\mathrm{mg} / \mathrm{L}$ & & 0.441 & 0.245 & $0.291^{\circ}$ \\
\hline $\mathrm{BMI}, \mathrm{kg} / \mathrm{m}^{2}$ & & -0.397 & 1.303 & -0.070 \\
\hline Model II & 0.445 & & & \\
\hline Hepcidin Peninsula, nM & & -0.215 & 0.096 & $-0.452^{b}$ \\
\hline Hemoglobin, $\mathrm{g} / \mathrm{dL}$ & & 3.548 & 2.278 & 0.383 \\
\hline Plasma ferritin, $\mu \mathrm{g} / \mathrm{L}$ & & -0.237 & 0.222 & -0.256 \\
\hline Transferrin receptor, $\mathrm{mg} / \mathrm{L}$ & & 0.245 & 0.326 & 0.147 \\
\hline $\mathrm{BMI}, \mathrm{kg} / \mathrm{m}^{2}$ & & -0.108 & 1.924 & -0.016 \\
\hline Model III & 0.525 & & & \\
\hline HepcidinAnalysis, nM & & -0.211 & 0.065 & $-0.545^{\mathrm{a}}$ \\
\hline Hemoglobin, $\mathrm{g} / \mathrm{dL}$ & & 3.566 & 1.799 & $0.401^{\mathrm{d}}$ \\
\hline Plasma ferritin, $\mu \mathrm{g} / \mathrm{L}$ & & -0.155 & 0.184 & -0.170 \\
\hline Transferrin receptor, $\mathrm{mg} / \mathrm{L}$ & & 0.460 & 0.255 & $0.304^{\mathrm{e}}$ \\
\hline $\mathrm{BMI}, \mathrm{kg} / \mathrm{m}^{2}$ & & -0.099 & 1.339 & -0.017 \\
\hline
\end{tabular}

${ }^{\mathrm{a}} \mathrm{p}<0.01,{ }^{\mathrm{b}} \mathrm{p}<0.05,{ }^{\mathrm{c}} \mathrm{p}=0.084,{ }^{\mathrm{d}} \mathrm{p}=0.059,{ }^{\mathrm{e}} \mathrm{p}=0.083$. Regression analysis with fractional iron absorption as dependent variable and hepcidin, hemoglobin, plasma ferritin, transferrin receptor and BMI as independent variables. Log transformed (Log10) data was used. $\mathrm{R}^{2}$ indicates the proportion of variance explained by the model. The b values (B) indicate the individual contribution of each predictor to the model. A positive value indicates a positive relationship between the predictor and the outcome, whereas a negative coefficient represents a negative relationship. Conversion factor to SI units for hemoglobin is 10 .

correlation between the DRG assay and the Peninsula assay was $r=0.893(p<0.001)$. The systematic bias was indicated by the slopes of regression lines, which were different from 1.00 (identity line $y=x$; indicated by the dashed line) for all the three measurement comparisons (Hepcidinanalysis.com vs. DRG, Hepcidinanalysis.com vs. Peninsula, DRG vs. Peninsula). This systematic bias was also visible in the Bland Altman plots (Figure 2A-C). However, correlation coefficients indicated a linear relationship for all comparisons.

\section{Discussion}

The predictive power of PHep measured by the three c-ELISA methods on FA is comparable to previous studies. Zimmermann et al. [12] showed a significant log correlation between iron absorption and PHep $(\mathrm{r}=-0.51$, $\mathrm{p}<0.001$ ) with a time-of-flight mass spectrometry (TOFMS) method. These findings are similar to our results obtained with the three different rapid c-ELISA methods $(r=-0.572, r=-0.602, r=-0.530$ for the Hepcidinanalysis.com-, the DRG- and the Peninsula method, respectively). PHep concentrations measured by the c-ELISA kits explain 36.3\% (DRG), 28.1\% (Peninsula) and 32.7\%
(Hepcidinanalysis.com) of the variance in FA. Similarly, Roe et al. [17] reported that PHep alone explained 36\% of variance in iron absorption when PHep assessed using TOF-MS. A further c-ELISA method (Intrinsic Life Sciences) was reported to similarly correlate with iron absorption from both foods and supplements, when data of both PHep and absorption were log transformed [18]. The Peninsula c-ELISA was previously reported to significantly predict iron absorption using log-transformed data in both, a bivariate analysis with $\mathrm{R}^{2}=8.9 \%$ [19] and in a univariate association between erythrocyte iron incorporation and PHep with adjusted $\mathrm{R}^{2}=67 \%$ [20]. Including $\mathrm{Hb}, \mathrm{PF}$, TfR and BMI into a multiple regression analysis, the models explained 55.7\% (DRG), 44.5\% (Peninsula) and $52.5 \%$ (Hepcidinanalysis.com) of the variance in FA. Zimmermann et al. [12] reported a lower explanation of variance in iron absorption (28\%) in their multiple regression model. This may be possibly due to differences in study design as we expected larger variations in both absorption and PHep levels in a study examining the effect of iron challenge on PHep and subsequent day iron bioavailability [8].

We compared two commercially available c-ELISA PHep assays to the c-ELISA from the Hepcidinanalysis.com initiative from the Radboud University Medical Centre, which has been fully validated, including a comparison 
A
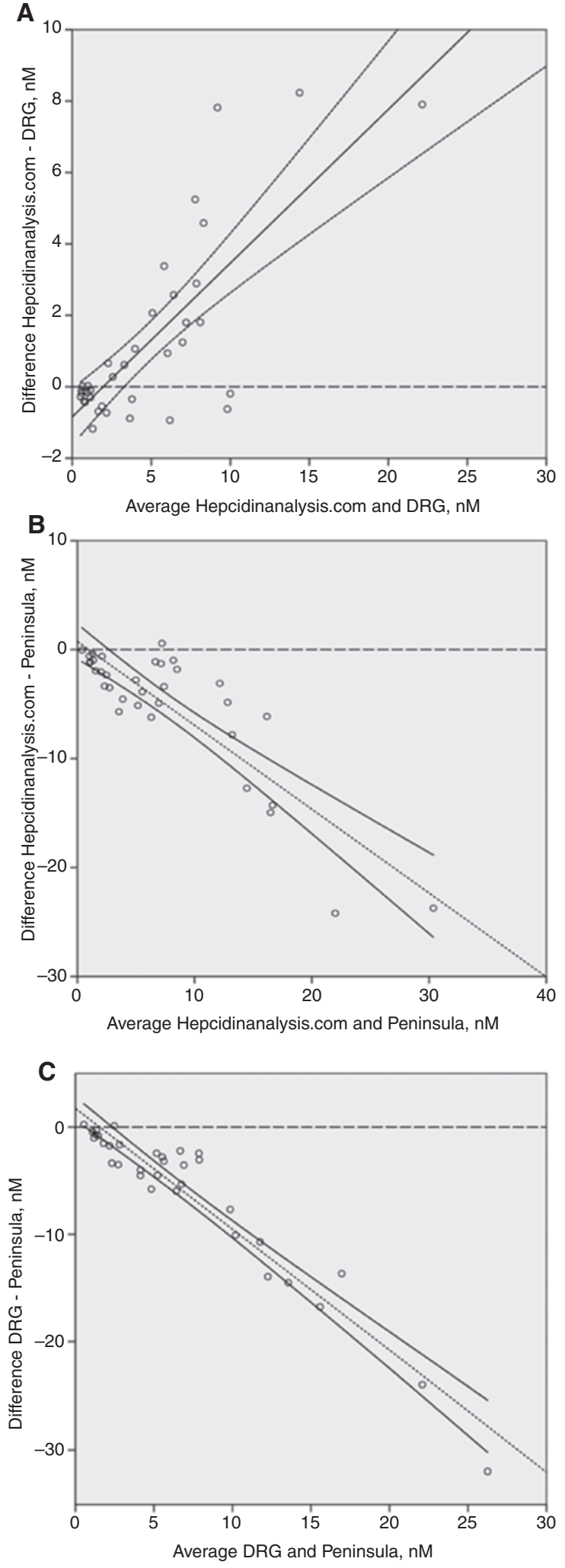
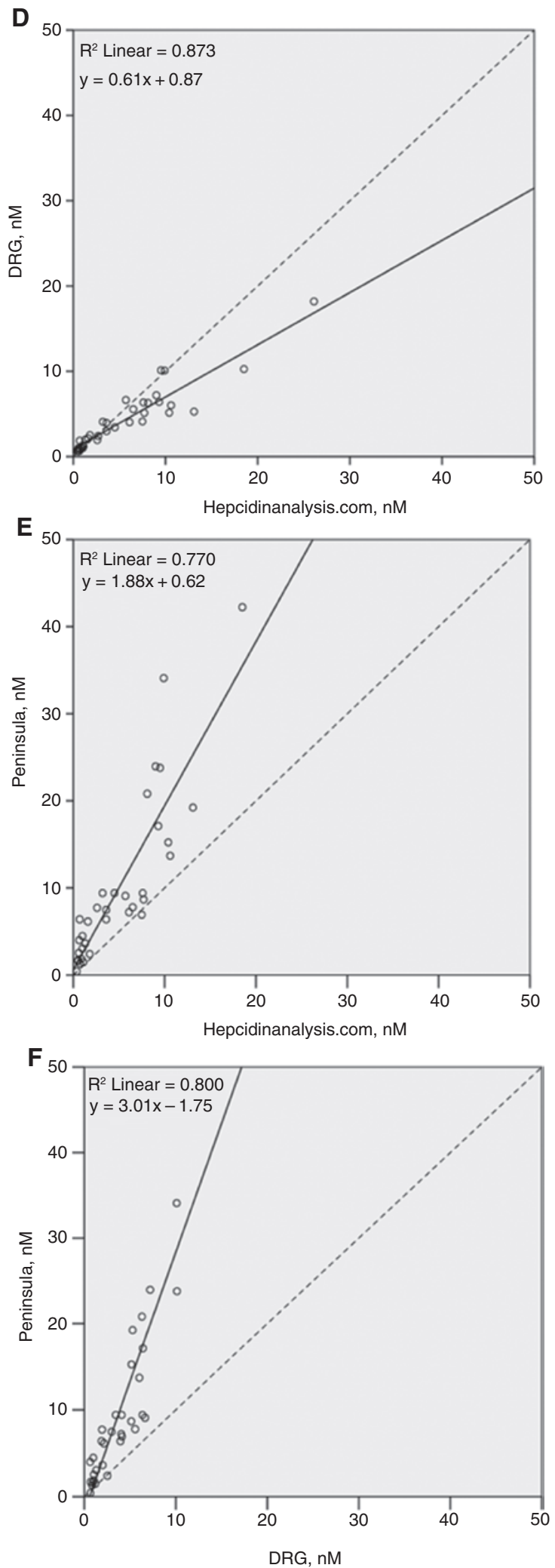

Figure 2: Method equivalence and correlation analysis between the three hepcidin c-ELISA assays.

Left panel: Bland-Altman plots for assessment of method equivalence, with regression lines (dotted lines) and corresponding $95 \%$ confidence intervals (dashed lines). (A) Hepcidinanalysis.com and DRG; (B) Hepcidinanalysis.com and Peninsula; (C) DRG and Peninsula. Right panel: Correlations for methods comparison, with the identity line $(y=x)$ indicated by the dashed line. (D) Hepcidinanalysis.com and DRG; (E) Hepcidinanalysis.com and Peninsula; (F) DRG and Peninsula. 
with WCX- TOF-MS [11]. Linear correlations between PHep values obtained with the DRG-, the Peninsula- and the Hepcidinanalysis.com assays were generally high. This indicates calibration and not heterogeneity in the measurement as major cause of the lack of equivalence, as also shown by a previous published study [21]. The significant systematic bias between the different methods was also indicated by the slopes of regression lines, which were different from 1 for all method comparisons. Bland Altman plots revealed large differences between values obtained using different methods. Compared to the Hepcidinanalysis.com assay, at PHep concentrations $>7.17 \mathrm{nM}$ the DRG assay underestimated PHep concentrations, whereas the Peninsula assay overestimated PHep concentrations (Figure 2, left panel).

We expected differences between PHep values measured with different methods, as previous round robin studies reported large systematic biases between different PHep assays [22, 23]. A direct comparison between DRG and Peninsula assays has also been reported by Wray et al. [24] and showed similar results. The large between assay variability could be due to several factors, including different calibration solutions [21], PHep aggregation of either the standard solution or the sample and/or PHep binding to $\alpha_{2}$ macroglobuline or albumin [25, 26]. Our results confirm that absolute PHep values from studies that have used different assays cannot be compared. Despite the large systematic differences between assays, the assays perform well; CVs are acceptable and similar for the DRG and Peninsula assays. The intra-run intersample variability (biological variability) was $109.7 \%$ for the DRG kit and $55.7 \%$ for the Peninsula kit, which were clearly higher than the intra-run intra-sample variabilities (13.9\% for the DRG and $11.6 \%$ for the Peninsula) [27] indicating that both methods are useful to distinguish samples of different PHep concentrations. Compared to the Peninsula assay, the DRG assay had shorter incubation times and the assay appears to have larger range of detection (according to the manufacturer concentrations up to $29.04 \mathrm{nM}$ can be measured). In contrast, using the Peninsula method, dilution of samples is recommended if PHep concentrations are expected to be higher than $8.96 \mathrm{nM}$. In addition, sample analysis with the DRG assay requires a lower sample volume $(20 \mu \mathrm{L} /$ well $)$ than analysis with the Peninsula method ( $50 \mu \mathrm{g} /$ well). Nonetheless, the intra-sample variability tended to be lower in the Peninsula assay.

Limitations of this study include the small sample size as the number of replicates measured for assessing the analytical performance for both intra-assay and interassay CV were low. We also did not attempt a full analytical performance assessment of the Peninsula assay, which has seven different protocols provided by the manufacturer. We have chosen the most commonly used protocol for a rapid determination of PHep. While we cannot exclude pre-analytical bias affecting our results, such as the possibility of PHep aggregate formations and breakdown products, this would be inconsistent with the similar predictive power for each of the three tested methods for bioavailability. Samples were stored frozen in separate similarly sized containers and not thawed between the first PHep measurements with Hepcidinanalysis.com and with the DRG- and the Peninsula kit, respectively. Strengths of this study were that we analyzed samples that provided a large range in PHep concentrations. However, we assessed samples from generally healthy subjects, where we would not expect any presence of PHep isoforms in plasma due to infection/inflammation or other conditions [4, 11]. Another strength of the study was the prediction of biological relevance by use of erythrocyte incorporation of orally administered stable isotopes, the gold standard measure of iron bioavailability.

In contrast to previously marketed kits which assessed prohepcidin and not the biologically active hepcidin-25 isoform, and which did not correlate with iron absorption [28], our study demonstrates that several viable commercial alternatives exist to assess the biologically active hepcidin-25 isoform in human plasma of healthy subjects. Our data also confirm that large systematic differences exist between different PHep determination methods. We anticipate that future use of the recently identified secondary reference material by all assays will substantially reduce these differences by allowing harmonization of assays [21]. However, both the DRG and the Peninsula c-ELISA assays are suitable to assess PHep levels, even if measured values are not fully comparable.

Acknowledgments: We would like to thank Andrew Armitage, Weatherall Institute of Molecular Medicine University of Oxford, Oxford, UK for very valuable analytical advice on the calibration of the Peninsula measurement kit.

Author contributions: NUS and DM designed the study. NUS and EF did the hepcidin measurements with the two commercially available c-ELISA assays. NUS analyzed the data and wrote the first draft of the manuscript. All authors contributed to the final version of the manuscript. All the authors have accepted responsibility for the entire content of this submitted manuscript and approved submission.

Research funding: None declared.

Employment or leadership: DWS is an employee of Radboud University and Medical Centre that offers high quality hepcidin measurements to the scientific, medical and pharmaceutical community, at a fee for service basis. 
Honorarium: None declared.

Competing interests: The funding organization(s) played no role in the study design; in the collection, analysis, and interpretation of data; in the writing of the report; or in the decision to submit the report for publication.

\section{References}

1. Pigeon C, Ilyin G, Courselaud B, Leroyer P, Turlin B, Brissot $P$, et al. A new mouse liver-specific gene, encoding a protein homologous to human antimicrobial peptide hepcidin, is overexpressed during iron overload. J Biol Chem 2001;276:7811-9.

2. Nemeth E, Valore EV, Territo M, Schiller G, Lichtenstein A, Ganz T. Hepcidin, a putative mediator of anemia of inflammation, is a type II acute-phase protein. Blood 2003;101:2461-3.

3. Nemeth E, Tuttle MS, Powelson J, Vaughn MB, Donovan A, Ward DM, et al. Hepcidin regulates cellular iron efflux by binding to ferroportin and inducing its internalization. Science 2004;306:2090-3.

4. Girelli D, Nemeth E, Swinkels DW. Hepcidin in the diagnosis of iron disorders. Blood 2016;127:2809-13.

5. Theurl I, Aigner E, Theurl M, Nairz M, Seifert M, Schroll A, et al. Regulation of iron homeostasis in anemia of chronic disease and iron deficiency anemia: diagnostic and therapeutic implications. Blood 2009;113:5277-86.

6. van Santen S, van Dongen-Lases EC, de Vegt F, Laarakkers CM, van Riel PL, van Ede AE, et al. Hepcidin and hemoglobin content parameters in the diagnosis of iron deficiency in rheumatoid arthritis patients with anemia. Arthritis Rheum 2011;63:3672-80.

7. Bregman DB, Morris D, Koch TA, He A, Goodnough LT. Hepcidin levels predict nonresponsiveness to oral iron therapy in patients with iron deficiency anemia. Am J Hematol 2013;88:97-101.

8. Moretti D, Goede JS, Zeder C, Jiskra M, Chatzinakou V, Tjalsma $\mathrm{H}$, et al. Oral iron supplements increase hepcidin and decrease iron absorption from daily or twice-daily doses in iron-depleted young women. Blood 2015;126:1981-9.

9. Krause A, Neitz S, Magert HJ, Schulz A, Forssmann WG, Schulz-Knappe P, et al. LEAP-1, a novel highly disulfide-bonded human peptide, exhibits antimicrobial activity. FEBS letters 2000;480:147-50.

10. Park CH, Valore EV, Waring AJ, Ganz T. Hepcidin, a urinary antimicrobial peptide synthesized in the liver. J Biol Chem 2001;276:7806-10.

11. Kroot JJ, Laarakkers CM, Geurts-Moespot AJ, Grebenchtchikov $\mathrm{N}$, Pickkers $\mathrm{P}$, van Ede AE, et al. Immunochemical and massspectrometry-based serum hepcidin assays for iron metabolism disorders. Clin Chem 2010;56:1570-9.

12. Zimmermann MB, Troesch B, Biebinger R, Egli I, Zeder C, Hurrell RF. Plasma hepcidin is a modest predictor of dietary iron bioavailability in humans, whereas oral iron loading, measured by stable-isotope appearance curves, increases plasma hepcidin. Am J Clin Nutr 2009;90:1280-7.

13. Erhardt JG, Estes JE, Pfeiffer CM, Biesalski HK, Craft NE. Combined Measurement of Ferritin, Soluble Transferrin Receptor, Retinol Binding Protein, and C-Reactive Protein by an Inexpensive, Sensitive, and Simple Sandwich Enzyme-Linked Immunosorbent Assay Technique. J Nutr 2004;134:3127-32.
14. Pasricha SR, Atkinson SH, Armitage AE, Khandwala S, Veenemans J, Cox SE, et al. Expression of the iron hormone hepcidin distinguishes different types of anemia in African children. Sci Transl Med. 2014;6:235re3.

15. Wegmuller R, Bah A, Kendall L, Goheen MM, Mulwa S, Cerami $C$, et al. Efficacy and safety of hepcidin-based screen-andtreat approaches using two different doses versus a standard universal approach of iron supplementation in young children in rural Gambia: a double-blind randomised controlled trial. BMC Pediatr 2016;16:149.

16. Bland JM, Altman DG. Statistical methods for assessing agreement between two methods of clinical measurement. Lancet. 1986;i:307-10.

17. Roe MA, Collings R, Dainty JR, Swinkels DW, Fairweather-Tait SJ. Plasma hepcidin concentrations significantly predict interindividual variation in iron absorption in healthy men. Am J Clin Nutr 2009;89:1088-91.

18. Young MF, Glahn RP, Ariza-Nieto M, Inglis J, Olbina G, Westerman $M$, et al. Serum hepcidin is significantly associated with iron absorption from food and supplemental sources in healthy young women. Am J Clin Nutr 2009;89:533-8.

19. Cusick SE, Opoka RO, Abrams SA, John CC, Georgieff MK, Mupere E. Delaying Iron Therapy until 28 Days after Antimalarial Treatment Is Associated with Greater Iron Incorporation and Equivalent Hematologic Recovery after 56 Days in Children: A Randomized Controlled Trial. J Nutr 2016;146:1769-74.

20. Prentice AM, Doherty CP, Abrams SA, Cox SE, Atkinson SH, Verhoef $\mathrm{H}$, et al. Hepcidin is the major predictor of erythrocyte iron incorporation in anemic African children. Blood 2012;119:1922-8.

21. van der Vorm LN, Hendriks JC, Laarakkers CM, Klaver S, Armitage AE, Bamberg A, et al. Toward worldwide hepcidin assay harmonization: identification of a commutable secondary reference material. Clin Chem 2016;62:993-1001.

22. Kroot JJC, Kemna EHJM, Bansal S, Busbridge M, Campostrini $\mathrm{N}$, Girelli $\mathrm{D}$, et al. Results of the first international round robin for the quantification of urinary and plasma hepcidin: Need for standardization. Blood 2008;112:50-1.

23. Kroot JJC, van Herwaarden AE, Tjalsma H, Jansen RTP, Hendriks JCM, Swinkels DW. Second round robin for plasma hepcidin methods: First steps toward harmonization. Am J Hematol 2012;87:977-83.

24. Wray K, Allen A, Evans E, Fisher C, Premawardhena A, Perera L, et al. Hepcidin detects iron deficiency in Sri Lankan adolescents with a high burden of hemoglobinopathy: A diagnostic test accuracy study. Am J Hematol 2017;92:196-203.

25. Peslova G, Petrak J, Kuzelova K, Hrdy I, Halada P, Kuchel PW, et al. Hepcidin, the hormone of iron metabolism, is bound specifically to alpha-2-macroglobulin in blood. Blood 2009;113:6225-36.

26. Itkonen O, Stenman UH, Parkkinen J, Soliymani R, Baumann $\mathrm{M}$, Hamalainen E. Binding of hepcidin to plasma proteins. Clin Chem 2012;58:1158-60.

27. Crowther JR. The ELISA Guidebook. Second Edition. Totowa, NJ, USA: Springer Protocols, 2009.

28. Roe MA, Spinks C, Heath AL, Harvey LJ, Foxall R, Wimperis J, et al. Serum prohepcidin concentration: no association with iron absorption in healthy men; and no relationship with iron status in men carrying HFE mutations, hereditary haemochromatosis patients undergoing phlebotomy treatment, or pregnant women. Br J Nutr 2007;97:544-9. 